\title{
Occurrence of Dental Trauma in a Group of Children with Autistic Spectrum Disorder
}

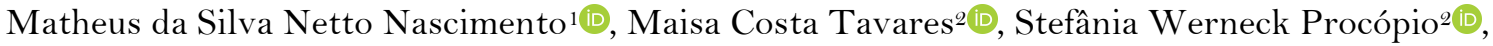 \\ Camila Faria Carrada ${ }^{\circledR}$, Flávia Almeida Ribeiro Scalioni ${ }^{\oplus}$, Saul Martins Paiva ${ }^{\circledR}$, Rosangela \\ Almeida Ribeiro 4
}

${ }^{1}$ School of Dentistry, Federal University of Juiz de Fora, Juiz de Fora, MG, Brazil.

'Department of Child and Adolescent Oral Health, School of Dentistry, Federal University of Minas Gerais, Belo Horizonte, MG, Brazil.

${ }^{3}$ Department of Paediatric Dentistry, School of Dentistry, School of Medical Sciences, Juiz de Fora, MG, Brazil.

${ }^{4}$ Department of Social and Pediatric Dentistry, School of Dentistry, Federal University of Juiz de Fora, Juiz de Fora, MG, Brazil.

Correspondence: Camila Faria Carrada, Faculdade de Odontologia, Universidade Federal de Minas Gerais, Avenida Antônio Carlos 6627, Pampulha, Belo Horizonte, MG, Brazil.31270-901. E-mail: camilacarrada_89@,hotmail.com

Academic Editor: Alessandro Leite Cavalcanti

Received: 14 April 2021 / Review: 19 July 2021 / Accepted: 02 August 2021

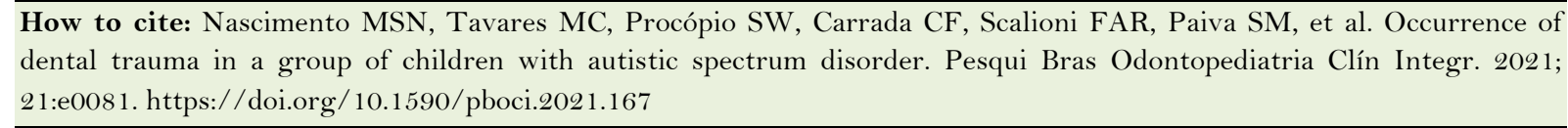

\begin{abstract}
Objective: To assess the occurrence of dental trauma in a group of children with Autistic Spectrum Disorder (ASD) in comparison to children without the disorder. Material and Methods: This is a crosssectional study conducted at the Department of Children and Adolescents Health in the Department of Health of Juiz de Fora, Brazil. The study included individuals with and without ASD, between three and 16 years old, and their parents/caregivers. Children/adolescents were assessed for dental trauma by clinical examination. All exams were performed by a trained and calibrated examiner (MCT), and intra-examiner reliability was previously established $($ Kappa $=0.93)$. The Socio-demographic status was reported by parents/caregivers. Data analysis included descriptive statistics and generation of frequency distributions. Fisher's exact test was used to evaluate the association between groups of children/adolescents with and without ASD about the presence of dental trauma. The significance level was set at $p<0.05$. Results: Sixty children of both sexes participated in the study, thirty with a diagnosis of ASD and thirty without. The age ranging from 3 to 13 years, with an average of $7.5 \pm 3.2$ years. Children with ASD had a higher frequency of dental trauma than children without ASD $(\mathrm{p}=0.02)$, and the most frequent type of trauma was enamel fracture $(57.10 \%)$, followed by enamel/dentin fracture without pulp exposure $(42.90 \%)$. Conclusion: Children with ASD, when compared to children who did not have ASD, had a higher occurrence of dental trauma.
\end{abstract}

Keywords: Autism Spectrum Disorder; Oral Health; Habits; Tooth Injuries. 


\section{Introduction}

Autistic Spectrum Disorder (ASD) is a chronic neurological development disorder characterized by impaired interaction and social communication and restricted and repetitive patterns of behavior, interests, and activities [1]. Clinical symptoms are noticeable in children over the age of 1.5-2 years due to irregular neuronal connections. The ASD affects the communicational, behavioral, and social areas [2]. This disorder affects more males than females, and more than $70.00 \%$ of individuals have associated conditions. Motor abnormalities are present in individuals with ASD, such as motor delay, hypotonia, catatonia, deficits in coordination and movement planning, gait and balance apraxia [3]. The World Health Organization estimates that one in 160 children in the world has ASD [4]. New data, however, show that the current prevalence is one in 59 children [5].

Individuals with ASD do not appear to have specific characteristics regarding oral health. Some authors consider that these individuals may present an increased risk of oral diseases such as dental caries, periodontal disease, parafunctional habits, malocclusion, and dental trauma [6-13]. Certain conditions can appear caused by behaviors related to ASD, such as communication limitations, self-injurious behavior, restrictive eating habits, use of medication, resistance to oral hygiene, and hyposensitivity to pain [7].

Dental trauma (DT) is a common health problem that affects a large part of the younger population. The prevalence of DT is variable, with an estimated average of $17.50 \%$ [14], although it can affect up to $62.10 \%$ of preschoolers [15]. Children with special needs have a higher risk of DT than normoreactive children due to characteristics related to cognitive, psychomotor, and behavioral impairment [16-18].

There is no consensus in the literature regarding whether DT is significantly more frequent in ASD. While some authors [18] report a significantly higher prevalence of DT in ASD patients, other authors [19] have observed this frequency to be similar between individuals with and without ASD. Additionally, Andrade et al. [20] determined the prevalence of DT in an ASD group to be lower than in a control group. Therefore, studies addressing this subject need to be encouraged in different populations to evaluate the true association between ASD and DT.

The DT management represents a major challenge in children with ASD, as they may be unable to cooperate during dental care. Therefore, the prevention of DT is important; however, it is necessary to assess the magnitude of DT in these children before designing preventive measures [8,21]. Thus, the aim of this study was to determine the occurrence of DT in children with ASD and to compare its occurrence in children without ASD.

\section{Material and Methods}

Ethical Considerations

This study was approved by the Human Research Ethics Committee of the Federal University of Minas Gerais, in accordance with the resolution of the National Health Council (CNS), December 12,2012 (Protocol number no. 3.434.537). Parents/caregivers received information regarding the objectives and importance of the research and signed a Free and Informed Consent Form authorizing the participation of their children.

\section{Sample Characteristics and Study Design}

This was a cross-sectional study conducted at a selected ASD center in Juiz de Fora, State of Minas Gerais, Brazil. Families of all children/adolescents assisted in this Center were invited to participate of the 
study, but only the ones that returned the informed consent participated. This outpatient clinic is attached to the Department of Children and Adolescents Health in the Department of Health of Juiz de Fora.

The inclusion criteria were individuals with and without ASD until 19 years old. ASD children were registered with the outpatient clinic for ASD. Individuals without ASD were selected among children attending routine pediatric consultations in Department of Pediatric Dentistry of the School of Dentistry of Federal University of Juiz de Fora, who did not have any syndrome or disorder. Individuals with ASD and without ASD were matched by age and socioeconomic status with a 1:1 pairing. All individuals with and without ASD whose parents agreed to participate in the study were recruited from November 2019 to March 2020. Children and adolescents with and without ASD whose behavior proved to be inappropriate for the clinical examination were excluded.

\section{Data Collection}

Clinical examination of all the children with ASD was performed while the child was seated on a regular chair. Children without ASD were examined in the School of Dentistry with similar conditions. All examinations were performed by one trained and calibrated examiner (MCT). Intraexaminer reliability were previously established $($ kappa $=0.93)$. The upper and lower incisors were cleaned and dried with gauze prior to the clinical exam. The DT was diagnosed based on the criteria proposed by Andreasen and Andreasen and was classified as enamel fracture and enamel/dentin fracture with or without pulp exposure. Root fractures and alveolar fractures were not recorded because radiography could not be used due to operational limitations $[22]$.

Parents/caregivers answered a questionnaire that provided information on child's sex, age, position in the family and previous visit to the dentist, mother's and father's age, mother's and father's years of schooling (categorized as $\leq 8$ years and $>8$ years), family income (categorized as $\leq 2$ times and $>2$ times the Brazilian minimum wage) and household overcrowding.

\section{Data Analysis}

Statistical Package for the Social Sciences (IBM SPSS, version 20, Chicago, IL, USA) was used to enter and analyze data obtained in this study. Data analysis included descriptive statistics and generation of frequency distributions. Fisher's exact test was used to evaluate the association between groups of children/adolescents with and without ASD about the presence of dental trauma.

\section{Results}

A total of 32 children with ASD were eligible for the study. Two children (6.30\%) were not included in the final sample due to incomplete data of the questionnaire applied to parents/caregivers. The study sample consisted of a total of 60 children, 30 children with ASD and 30 children without ASD. The age in both the groups ranged from 3-13 years with a mean age of $7.5 \pm 3.2$ years.

Table 1 shows the characteristics of study participants. Of the caregivers interviewed, both in the group with ASD (86.70\%) and in the group without ASD (83.30\%), the majority were mothers. The mean of mothers' age in group with ASD (37.6 \pm 7.3 years) was lower than the mean of the mothers' age in group without ASD (39.8 \pm 8.1 years). Most mothers of both groups $(70.00 \%)$ had more than 8 years of schooling. 
Regarding fathers, the mean age in group with ASD (42.1 \pm 12.4 years) was higher than the mean age in group without ASD $(40.3 \pm 11.3$ years). In the group with ASD, most parents had more than 8 years of schooling $(43.30 \%)$. In the group without ASD, most parents had less than 8 years of schooling (43.30\%). In both groups, $93.30 \%$ of individuals have a family income equal or less than two minimum wages. The household overcrowding in ASD group is up to four people in $83.30 \%$ of the cases. In the group without ASD, the household overcrowding was up to four people in $73.30 \%$ of the cases.

Table 1. Characteristics of study participants.

\begin{tabular}{|c|c|c|}
\hline Variables & $\begin{array}{c}\text { Group with ASD } \\
\mathrm{N}(\%)\end{array}$ & $\begin{array}{c}\text { Group without ASD } \\
\mathrm{N}(\%)\end{array}$ \\
\hline \multicolumn{3}{|l|}{ Sex } \\
\hline Female & $3(10.00)$ & $11(36.70)$ \\
\hline Male & $27(90.00)$ & $19(63.30)$ \\
\hline \multicolumn{3}{|l|}{ Age } \\
\hline Mean (SD) & $7.58( \pm 3.2)$ & $7.58( \pm 3.2)$ \\
\hline \multicolumn{3}{|l|}{ Position in the Family } \\
\hline Oldest Son & $4(13.30)$ & $6(20.00)$ \\
\hline Middle Child & $2(6.40)$ & $7(23.30)$ \\
\hline Youngest Son & $18(60.00)$ & $12(40.00)$ \\
\hline Only Child & $6(20.00)$ & $5(16.70)$ \\
\hline \multicolumn{3}{|l|}{ Caregiver Interviewed } \\
\hline Mother & $26(86.70)$ & $25(83.30)$ \\
\hline Father & $4(13.30)$ & $4(13.30)$ \\
\hline Grandparents & $\mathrm{o}(0.0)$ & $1(3.30)$ \\
\hline \multicolumn{3}{|l|}{ Previous Visit to the Dentist } \\
\hline Yes & $13(43.30)$ & $20(66.70)$ \\
\hline No & $17(56.70)$ & $10(33.30)$ \\
\hline \multicolumn{3}{|l|}{ Mother's age } \\
\hline Mean (SD) & $37.65( \pm 7.3)$ & $39.82( \pm 8.1)$ \\
\hline \multicolumn{3}{|l|}{ Mother's Years of Schooling } \\
\hline$\leq 8$ Years & $9(30.00)$ & $9(30.00)$ \\
\hline$>8$ Years & $21(70.00)$ & $21(70.00)$ \\
\hline \multicolumn{3}{|l|}{ Father's Age } \\
\hline Mean (SD) & $42.1( \pm 12.4)$ & $40.3( \pm 11.3)$ \\
\hline \multicolumn{3}{|l|}{ Father's Years of Schooling } \\
\hline$\leq 8$ Years & $13(36.70)$ & $17(43.30)$ \\
\hline$>8$ Years & $17(43.30)$ & $13(36.70)$ \\
\hline \multicolumn{3}{|l|}{ Family income } \\
\hline$\leq 2$ Brazilian Minimum Wages & $28(93.30)$ & $28(93.30)$ \\
\hline$>2$ Brazilian Minimum Wages & $2(6.70)$ & $2(6.70)$ \\
\hline \multicolumn{3}{|l|}{ Household Overcrowding } \\
\hline Up to 4 People & $25(83.30)$ & $22(73.30)$ \\
\hline Until 4 People & $5(16.70)$ & $8(26.70)$ \\
\hline
\end{tabular}

Table 2 shows the comparison between groups of children with and without ASD about the presence of dental trauma. Children with ASD had a higher frequency of dental trauma compared to children without $\operatorname{ASD}(p=0.02)$. Of the seven individuals with ASD who suffered dental trauma, one was female and was one of the four individuals with ASD (57.10\%) who suffered an enamel fracture. Three individuals with ASD (42.90\%) suffered enamel/dentin fractures without pulp exposure. The only individual without ASD with dental trauma was male and suffered enamel fracture. 
Table 2. Comparison between groups of children/adolescents with and without ASD about the presence of dental trauma.

\begin{tabular}{lccc}
\hline \multicolumn{1}{c}{ Dental Trauma } & Group with ASD & Group without ASD & p-value* $^{*}$ \\
& N $(\%)$ & N $(\%)$ & 0.02 \\
\hline Absence & $23(76.30)$ & $29(96.70)$ & \\
Presence & $7(23.30)$ & $1(3.30)$ &
\end{tabular}

\section{Discussion}

This study provides information on the occurrence of DT in children with ASD, in a certain age group, and the comparison with the occurrence of this condition in normoreactive children of the same age.

The results showed that DT were more prevalent in children with ASD compared to their normoreactive counterparts (with ASD 23.30\% and without ASD 3.30\%). This reinforces results found in a similar study, which showed a significantly higher prevalence of DT among the study group with ASD $(25.70 \%)$ compared to the control group $(16.30 \%)[\mathrm{p}=0.012][8]$. This result can possibly be explained by the characteristics of individuals with ASD, who have functional changes that can affect their motor coordination and balance, regardless of age [3]. When analyzing the epidemiology of DT in normoreactive individuals, it is observed that the highest prevalence of this condition occurs during the period when the child learns to crawl, walk, run and interact with his physical environment and when they perform physical and leisure activities, being able to lead to falls and collisions with people or objects [23]. Individuals with ASD often have difficulty in developing reciprocal social interactions and impaired communication skills, thus leading to greater isolation $[18,24]$. Thus, it is suggested that the risk factors for DT in individuals with ASD are different from normoreactive individuals, since they present characteristics opposite to the determinants that increase the chance for this oral condition, such as little participation in collective activities, which could lead to falls and physical impacts frequently [20]. Previous studies have reported that falls in individuals with ASD were associated with loss of stability during walking, suggesting that this is the main risk factor for DT in this population [18,24]. DT injuries also arise as a result of self-injury, through a characteristic behavior in individuals with ASD, which is often rhythmic and repetitive [7,25].

However, other studies have shown a similar prevalence $[16,18,19,26]$ or lower [20] of DT in children with ASD compared to normoreactive children. It has been suggested as the main reason for this low prevalence that the environment of children with ASD is more protected and supervised by those responsible $[6]$.

Factors such as low education and advanced maternal age have a high relationship with low adherence to the treatment of DT and the low importance attached to the monitoring of cases [27,28]. However, it was not the objective of this study to verify this association between these characteristics of parents/caregivers with the occurrence of DT, but, according to the data present in Table 1, it appears that there is no difference between the means used in the two groups.

In the present study, the type of DT most often found was enamel fractures in permanent teeth, which corroborates with results found by other authors who also evaluated DT in populations with ASD [7,8,18,25,29-31]. The upper central incisors are the most affected teeth [16,24,29,30], which can be justified due to their position in the arch, which makes them more exposed to trauma [18,32]. In children without ASD, coronary fractures are also the most commonly reported injuries to permanent teeth and dislocation injuries are the most frequent DT in primary dentition [25,33]. 
A higher frequency of DT in children with ASD was found in males. However, this result should be interpreted with caution since only three females participated in the ASD group in this study. Previous findings in the literature also showed a higher frequency of DT in individuals with male ASD [7,16,30,31]. However, others researches show a higher frequency in individuals with ASD in females [17-19,25], which is explained by the possibility that the characteristics of ASD in girls are more severe [18].

Few studies have investigated DT in children with ASD [19,25]. Considering that DT is frequently found in clinical practice, the investigation of these injuries in individuals with ASD becomes relevant for the implementation of preventive and interceptive strategies for this population [20]. The inadequate management of DT can lead to complications, worsening the prognosis of the affected tissues [33].

The present study has limitations that must be considered. Some cases of DT may have been missed because of lack of recall on the part of parents, or because diagnosis of certain types of DT may require more than just a clinical examination [22]. Since the cross-sectional design does not allow establishing a temporal relationship between DT and independent variables, longitudinal studies are needed to assess the causal relationship between influence of having ASD on dental trauma. In addition, it must be pointed out children and adolescents with and without ASD were exclude due to the impossibility of performing the clinical examination. Since difficult behavior is a characteristic of children with the disorder, this exclusion criterion could be interpreted as a study limitation. Therefore, future studies on the subject with larger samples should include ASD individuals with difficult-to-behave.

In view of the difficulty in the behavioral approach of individuals with ASD during dental treatment, the importance of preventive programs related to oral disorders prevalent in this population, such as DT, is emphasized. In addition, based on the fact that children with ASD have difficulty communicating, periodic dental consultations are encouraged, since individuals with ASD have less access to the dentist (43.30\%) when compared to children without $(66.70 \%)$, as observed in the present study. This is intended to function as a form of controlling and early identification of DT, for a better approach and treatment prognosis. Such recommendations are important in ensuring the well-being and quality of life of these patients.

\section{Conclusion}

Children with ASD, when compared to children who did not have ASD, had a higher occurrence of dental trauma.

\section{Authors' Contributions}

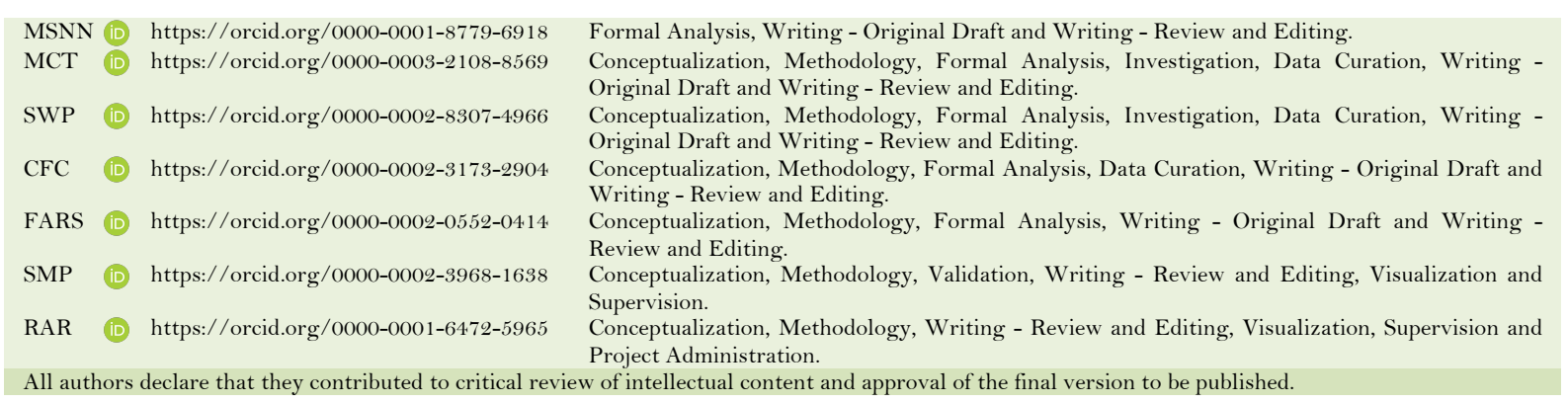

\section{Financial Support}

This study was supported by the Federal University of Juiz de Fora, the Coordenação de Aperfeiçoamento de Pessoal de Nível Superior Brasil (CAPES) - Finance Code 001, the Research Foundation of the State of Minas Gerais (FAPEMIG) and the National Council for Scientific and Technological Development (CNPQ) Brazil. 


\section{Conflict of Interest}

The authors declare no conflicts of interest.

\section{Data Availability}

The data used to support the findings of this study can be made available upon request to the corresponding author.

\section{References}

[1] American Psychiatric Association. Diagnostic and Statistical Manual of Mental Disorders. 5th. ed. Philadelphia: American Psychiatric; 2013. 992p.

[2] Bhat S, Acharya UR, Adeli H, Bairy GM, Adeli A. Autism: cause factors, early diagnosis and therapies. Rev Neurosci 2014; 25(6):841-50. https://doi.org/10.1515/revneuro-2014-0056

[3] Lai MC, Lombardo MV, Baron-Cohen S. Autism. Lancet 2014; 383(9920):896-910. https://doi.org/10.1016/So140-6736(13)61539-1

[4] World Health Organization. Autism spectrum disorders. Available from: http://www.who.int/news-room/fact sheets/detail/autism-spectrum-disorders. [Accessed on March 14, 2019].

[5] Baio J, Wiggins L, Christensen DL, Maenner MJ, Daniels J, Warren Z, et al. Prevalence of autism spectrum disorder among children aged 8 years - autism and developmental disabilities monitoring network, 11 sites, United States, 2014. MMWR Surveill Summ 2018; 67(6):1-23. https://doi.org/10.15585/mmwr.ss6706a1

[6] Sarnat H, Samuel E, Ashkenazi-Alfasi N, Peretz B. Oral health characteristics of preschool children with autistic syndrome disorder. J Clin Pediatr Dent 2016; 40(1):21-5. https://doi.org/10.17796/1053-4628-40.1.21

[7] Morales-Chávez MC. Oral health assessment of a group of children with autism disorder. J Clin Pediatr Dent 2017; 41(2):147-9. https://doi.org/10.17796/1053-4628-41.2.147

[8] Al-Sehaibany FS. Occurrence of traumatic dental injuries among preschool children with autism spectrum disorder. Pak J Med Sci 2018; 34(4):859-63. https://doi.org/10.12669/pjms.344.15681

[9] Fontaine-Sylvestre C, Roy A, Rizkallah J, Dabbagh B, dos Santos BF. Prevalence of malocclusion in Canadian children with autism spectrum disorder. Am J Orthod Dentofacial Orthop 2017; 152(1):38-41. https://doi.org/10.1016/j.ajodo.2017.02.014

[10] Marshall J, Sheller B, Williams BJ, Mancl L, Cowan C. Cooperation predictors for dental patients with autism. Pediatr Dent 2007; 29(5):369-76.

[11] Murshid EZ. Diet, oral hygiene practices and dental health in autistic children in Riyadh, Saudi Arabia. Oral Health Dent Manag 2014; 13(1):91-6.

[12] Qiao Y, Wu M, Feng Y, Zhou Z, Chen L, Chen F. Alterations of oral microbiota distinguish children with autism spectrum disorders from healthy controls. Sci Rep 2018; 8(1):1597. https://doi.org/10.1038/s41598-018-19982-y

[13] Silva SN, Gimenez T, Souza RC, Mello-Moura ACV, Raggio DP, Morimoto S, et al. Oral health status of children and young adults with autism spectrum disorders: systematic review and meta-analysis. Int J Paediatr Dent 2017; 27(5):388-98. https://doi.org/10.1111/ipd.12274

[14] Azami-Aghdash S, Azar FE, Azar FP, Rezapour A, Moradi-Joo M, Moosavi A, et al. Prevalence, etiology, and types of dental trauma in children and adolescents: systematic review and meta-analysis. Med J Islam Repub Iran 2015; 29(4):234.

[15] Viegas CM, Scarpelli AC, Carvalho AC, Ferreira FM, Pordeus IA, Paiva SM. Predisposing factors for traumatic dental injuries in Brazilian preschool children. Eur J Paediatr Dent 2010; 11(2):59-65.

[16] Altun C, Guven G, Yorbik O, Acikel C. Dental injuries in autistic patients. Pediatr Dent 2010; 32(4):343-6.

[17] Ferreira MCD, Guare RO, Prokopowitsch I, Santos MTBR. Prevalence of dental trauma in individuals with special needs. Dent Traumatol 2011; 27(2):113-6. https://doi.org/10.1111/j.1600-9657.2010.00961.x

[18] Habibe RCH, Ortega AOL, Guare RO, Diniz MB, Santos MTBR. Risk factors for anterior traumatic dental injury in children and adolescents with autism spectrum disorders: a case-control study. Eur Arch Paediatr Dent 2016; 17(2):75-80. https://doi.org/10.1007/s40368-015-0207-7

[19] Lam PP, Du R, Peng S, McGrath CP, Yiu CK. Oral health status of children and adolescents with autism spectrum disorder: A systematic review of case-control studies and meta-analysis. Autism 2020; 24(5):1047-66. https://doi.org/10.1177/1362361319877337

[20] Andrade NS, Dutra TTB, Fernandes RF, Moita Neto JM, Mendes RF, Prado Júnior RR. Retrospective study of dental trauma in children with autism spectrum disorders: a paired study. Spec Care Dentist 2016; 36(5):260-4. https://doi.org/10.1111/scd.12180

[21] Surabian SR. Dentistry's intrinsic link to provision of services for persons with disabilities. J Calif Dent Assoc 2013; 41(9):677-88.

[22] Corrêa-Faria P, Paiva SM, Pordeus IA, Ramos-Jorge ML. Influence of clinical and socioeconomic indicators on dental trauma in preschool children. Braz Oral Res 2015; 29:1-7. 
[23] Day PF, Flores MT, O'Connell AC, Abbott PV, Tsilingaridis G, Fouad AF, et al. International Association of Dental Traumatology guidelines for the management of traumatic dental injuries: 3. Injuries in the Primary Dentition. Dent Traumatol 2020; 36(4):343-59. https://doi.org/10.1111/edt.12576

[24] Silveira ALNMES, Magno MB, Soares TRC. The relationship between special needs and dental trauma. A systematic review and meta-analysis. Dent Traumatol 2020; 36(3):2 18-36. https://doi.org/10.1111/edt.12527

[25] Bagattoni S, Sadotti A, D'Alessandro G, Piana G. Dental trauma in Italian children and adolescents with special health care needs. A cross-sectional retrospective study. Eur J Paediatr Dent 2017; 18(1):23-6. https://doi.org/10.23804/ejpd.2017.18.01.05

[26] Du RY, Yiu CK, King NM, Wong VC, McGrath CP. Oral health among preschool children with autism spectrum disorders: A case-control study. Autism 2015; 19(6):746-51. https://doi.org/10.1177/1362361314553439

[27] Dantas VB, Alves AC, Scavuzzi AIF. Prevalência de trauma dental em crianças e adolescentes atendidos no NEPTI da FOUFBA. Rev ABENO 2019; 19(2):71-81. https://doi.org/10.30979/rev.abeno.v19i2.871

[28] Kramer PF, Feldens CA, Ruschel HC, Ferreira SH, Senna RA, Vargas-Ferreira F. Traumatic dental injuries and associated factors in children assisted in a school of Dentistry in Southern Brazil. Stomatos 2017; 23(45):28-38.

[29] Agbor AM, Sugim CFM, Tedong L, Naidoo S. Oral health status in children with autism spectrum disorder presenting in Yaoundé, Cameroon. Sch J Oto 2019; 1(5):102-6.

[30] Al-Batayneh OB, Owais AI, Al-Saydali MO, Waldman HB. Traumatic dental injuries in children with special health care needs. Dent Traumatol 2017; 33(4):269-75. https://doi.org/10.1111/edt.12334

[31] Galvão AKFDC, Ribeiro ILA, Cabral GMP, Ferreira MCD, Santos MTBR. Prevalence of tooth injuries in patients with neuropsychomotor disorder. Rev Odontol UNESP 2017; 46(6):351-6. https://doi.org/10.1590/1807-2577.06917

[32] Bourguignon C, Cohenca N, Lauridsen E, Flores MT, O'Connell AC, Day P, et al. International Association of Dental Traumatology guidelines for the management of traumatic dental injuries: 1. Fractures and luxations. Dent Traumatol 2020; 36(4):314-30. https://doi.org/10.1111/edt.12578

[33] Levin L, Day PF, Hicks L, O'Connell A, Fouad AF, Bourguignon C, et al. International Association of Dental Traumatology guidelines for the management of traumatic dental injuries: General introduction. Dent Traumatol 2020; 36(4):309-13. https://doi.org/10.1111/edt.12574 